\title{
TÉCNICA E TECNOLOGIA EM MARCUSE: DOMINAÇÃO OU EMANCIPAÇÃO?
}

\author{
ANDRÉ FRANCISCO FREIRE MONTEIRO ${ }^{1}$
}

\begin{abstract}
RESUMO: O presente trabalho analisa o pensamento de Herbert Marcuse, focando-se na questão da técnica e da tecnologia, em especial quando podem produzir a dominação ou a emancipação do homem. Com base em uma revisão bibliográfica, observa-se que Marcuse desponta como um dos primeiros seguidores da Teoria Critica a estudar os mecanismos de dominação, partindo da racionalidade tecnológica que se transforma em racionalidade política. $\mathrm{O}$ autor denuncia os contornos ideológicos característicos das sociedades capitalistas. Com base no texto do filósofo (Algumas implicações sociais da tecnologia moderna, 1941), verifica-se que técnica e tecnologia passam a ser empregadas como mecanismo de dominação e de controle da natureza.
\end{abstract}

PALAVRAS-CHAVE: Racionalidade tecnológica. Técnica. Tecnologia. Teoria crítica.

\begin{abstract}
This paper analyzes the philosophical thought of Herbert Marcuse on the technique and technology, especially when both may produce the domination or emancipation of the human being. Based on a literature review, it is observed that Marcuse stands out as one of the first of the Frankfurt School to study the mechanisms of domination, based on the technological rationality that turns into political rationality. The author denounces the characteristic ideological contours of capitalist societies. Based on the philosopher text (Some social implications of modern technology, 1941), it appears that technique and technology shall be used as a mechanism of domination and control of nature.
\end{abstract}

KEYWORDS: Critical theory. Technique. Technological rationality. Technology.

\section{INTRODUÇÃO}

O filósofo alemão Herbert Marcuse foi um dos primeiros pesquisadores a estudar os mecanismos de dominação tecnológica e política que surgiram com o desenvolvimento da sociedade moderna. Ele realizou estudos que foram fundamentais para a compreensão do avanço da ciência e das tecnologias que transformaram a vida humana. As suas interpretações sobre o funcionamento das sociedades industriais avançadas, do desenvolvimento da técnica e da tecnologia, das implicações sociais do desenvolvimento da tecnologia na sociedade 
moderna, continuam importantes para a compreensão da sociedade contemporânea, sobretudo no que tange às contradições sociais.

Marcuse tornou-se membro do Instituto de Pesquisa Social, conhecido como "Escola de Frankfurt", em 1933. O Instituto, a partir da década de 1930, começou a utilizar um conceito de Teoria Social crítica opondo-se à teoria tradicional de cunho positivista. Marcuse entende que um dos objetivos da Teoria Crítica é analisar o desenvolvimento da sociedade e examinar as alternativas históricas para melhoria da qualidade de vida, no sentido de minimizar a luta pela existência e aperfeiçoar os recursos materiais e intelectuais disponíveis.

A Teoria Crítica deve analisar as origens dos problemas; examinar a maneira como a sociedade está organizada em comparação com outras formas possíveis, buscando demonstrar as possibilidades reais de desenvolvimento e satisfação das necessidades humanas. Para tanto, ela parte de bases empíricas, isto é, da análise das condições objetivas de organização social, priorizando a forma como está estruturado o sistema de produção e o consumo para verificar as possibilidades de se produzir emancipação. Notadamente, Marcuse observa que no capitalismo o sistema de produção e consumo pré-condiciona os indivíduos e os condena à unidimensionalidade das condições de existência, tanto subjetivas quanto objetivas, inviabilizando a crítica e impedindo o afloramento de outras possibilidades históricas. Portanto, não produz emancipação, apenas aumenta a labuta pela existência, reproduzindo um estilo de vida pautado na troca da liberdade pelo conforto.

Dessa perspectiva, tem-se como objetivo compreender as implicações sociais do desenvolvimento da técnica e da tecnologia, mostrando as potencialidades tanto da dominação quanto da emancipação que elas podem gerar. Como base para a análise utiliza-se o texto "Algumas implicações sociais da tecnologia moderna", um artigo publicado originalmente em 1941 e, no Brasil, publicado recentemente numa coletânea organizada por Douglas Kellner, editor de Marcuse.

Este artigo pretende responder a algumas contradições que surgem no estudo da Teoria Crítica sobre a tecnologia, desenvolvido por Herbert Marcuse. As questões são: a) quais as concepções de Herbert Marcuse sobre a técnica, a tecnologia e a razão tecnológica desenvolvidas no ensaio "Algumas implicações sociais da tecnologia moderna"? b) quais as implicações sociais do desenvolvimento da técnica e da tecnologia nas sociedades capitalistas apontadas pelo filósofo?; c) qual o potencial emancipatório da Técnica? Responder a essas questões parece ser de fundamental importância para entendermos a função da técnica e da tecnologia na sociedade contemporânea, bem como os meios para instauração de uma realidade social pacífica.

Para a realização deste trabalho foi utilizado a metodologia da revisão bibliográfica, analisando-se as obras de Herbert Marcuse, principalmente o texto "Algumas implicações sociais da tecnologia moderna". Enquanto método, a Teoria Crítica da sociedade aponta para a importância da crítica negativa em relação à ciência positiva que orienta a tecnologia nas sociedades industriais, servindo ao capital enquanto perspectiva de valor. As contradições saltam aos olhos.

\section{Herbert Marcuse e o Instituto de Pesquisa Social}

Herbert Marcuse nasceu em 1898 e é um filósofo e sociólogo alemão que ficou bastante conhecido durante os anos de 1960, devido ao movimento estudantil ocorrido na Europa em maio de $1968^{2}$ e também por ter sido um dos membros da primeira geração do Instituto de Pesquisa Social de 
Frankfurt. Com 18 anos entrou para o exército alemão. Logo depois, ele permaneceu por dois anos filiado ao Partido Social Democrata alemão (PSD). Em 1919, cursou Germanística na Universidade de Humboldt de Berlim e depois estudou Filosofia e Economia Política na Universidade de Friburgo. Nesta mesma universidade realizou o doutorado, com a tese $O$ romance do artista alemão.

Marcuse começou a colaborar com o Instituto de Pesquisa Social de Frankfurt em 1933. Este Instituto foi fundando em fevereiro de 1923 na Universidade de Frankfurt. Apesar de estar integrado à Universidade, o Instituto mantinha independência em relação a ela, graças ao financiamento de um de seus membros, Felix Weil, que era filho de um rico imigrante exportador de trigo na Argentina.

Garl Gruenberg foi o primeiro diretor do Instituto de Pesquisa, porém, quando Herbert Marcuse passou a ser membro, a direção já tinha sido transferida para o filósofo e professor universitário Marx Horkheimer. Marx Horkheimer assumiu a direção do Instituto em 1930. Após sua nomeação, “[...] o Instituto desenvolveu um conceito de teoria social crítica que contrastava com a "teoria tradicional” (KELLNER, 1999, p. 22).

Os principais membros da primeira geração da Escola de Frankfurt ${ }^{3}$ foram Friedrich Pollock, Marx Horkheimer, Wittfogel, Erich Fromm, Leo Lowenthal, Gumperz, Franz Neumann, Theodor Adorno, Walter Benjamim e Herbert Marcuse. Esses intelectuais colaboravam com pesquisas e publicação de artigos na Revista ${ }^{4}$ do Instituto. "[...] também produziam críticas de teorias dominantes e conceitos de ideologia, filosofia e ciência social burguesas [...]”, e ainda efetuaram "[...] análises da transição do capitalismo liberal e de mercado para o capitalismo estatal e monopolista, incluindo análises do fascismo alemão" (KELLNER, 1999, p. 22).

Com o aumento do poder do Partido Nazista ${ }^{5}$ e a nomeação de Adolf Hitler ao cargo de chanceler em 1933, Horkheimer começou a negociar a transferência do Instituto para outros países, devido principalmente ao aumento do antissemitismo, sendo que a maioria dos membros do instituto vinha de famílias judaicas. No mesmo ano da nomeação de Hitler ao poder, o governo decretou o fechamento do Instituto. Em 1933, o Instituto emigrou para Genebra, na Suíça, e posteriormente, em 1934, transferiu-se para Nova Iorque, onde se manteve filiado à Universidade de Columbia e passou a ser um Instituto Internacional de Pesquisa Social, mantendo a sua autonomia em relação à nova universidade. Marcuse acompanhou o Instituto tanto na transferência para Genebra quanto para Nova Iorque, sendo que foi um dos responsáveis pela sua instalação nos Estados Unidos.

Segundo Freitag (1988), o período de consolidação do Instituto de Pesquisa Social é marcado pela Filosofia Social de Horkheimer. O foco de pesquisa do Instituto, em seu primeiro momento, sob a direção de Gruenberg, era compreender as formas que "[...] a classe operária enfrentava as crises específicas do capitalismo do início do século XX [...]". Em seguida, sob a coordenação de Horkheimer, o foco passou a ser saber os motivos que levaram "[...] a classe operária não ter assumido o seu destino histórico de revolucionar a ordem estabelecida [...]” (FREITAG, 1988, p. 15). E ainda, segundo Freitag (1988, p. 17), "a produção do Instituto nessa época da imigração para os Estados Unidos se reflete em [...] uma série de artigos fundamentais publicados na Revista, e que deram origem à criação da 'teoria crítica' [...]".

A partir de sua filiação ao Instituto, Marcuse passou a colaborar com a publicação da Revista. "Ele também escreveu alguns artigos explorando tanto a concepção de teoria crítica a guiar o seu trabalho teórico e o de seus colegas, quanto dando início a uma das principais marcas de sua teoria social: a crítica da ideologia e da cultura." (KLEIN, 2006, p. 8). 
É a partir da década de 1940 que os trabalhos de Marcuse passaram a se voltar para a compreensão das formas de dominação e controle da sociedade.

Marcuse foi um dos primeiros teóricos críticos das novas formas de dominação tecnológica e política nas sociedades industriais avançadas. Emerge assim dessa época como um importante teórico da tecnologia, do fascismo e das vicissitudes da sociedade industrial avançada- temas que desenvolveria em seus escritos posteriores à Segunda Guerra Mundial. (KELLNER, 1999, p. 24)

Na década de 1940, Marcuse estava nos Estados Unidos e as análises sobre o papel da técnica e da tecnologia no processo de dominação são influenciadas principalmente pelo funcionamento da sociedade americana, sociedade em que o capitalismo moderno estava em pleno avanço. Nela, a "[...] tecnologia, no sentido de um aparato de dominação produtor de uma racionalidade repressora do desenvolvimento da subjetividade crítica, encontra-se em seu estágio mais avançado [...]" (KLEIN, 2006, p. 23).

Em 1941, Marcuse publicou o seu primeiro livro, intitulado Razão e Revolução, onde "[...] introduziria Hegel, Marx e a teoria social ao público de língua inglesa e que iria delinear as origens e perspectivas do tipo de teoria social crítica que estavam sendo desenvolvidas pelo Instituto [...]" (KELLNER, 1999, p. 24). Nesse mesmo ano ele também publicou o ensaio "Algumas implicações sociais da tecnologia moderna", que trata sobre o processo de dominação tecnológica, a produção da escassez e o conformismo, surgidos a partir de mudanças ocasionadas na esfera da produção.

Segundo Pisani (2006), Marcuse estudou várias pesquisas americanas para elaboração da análise sobre as implicações do desenvolvimento da técnica e da tecnologia nas modernas sociedades industriais; ele utilizou várias monografias, relatórios e até mesmo documentos do governo para compreender o modus operandi desta sociedade. Recorreu principalmente às pesquisas de Thorstein Veblen que, segundo o filósofo $(1999$, p.78), "[...] foi um dos primeiros a concluir que a nova factualidade provinha do processo da máquina, a partir do qual se estendia sobre toda a sociedade"; e também de Lewis Mumdford, autor do texto "Técnica e Civilização", publicado em 1934.

Douglas Kellner (1999, p. 29) afirma que "a teoria crítica de Marcuse da técnica/tecnologia [...] diferencia as características negativas dos potenciais positivos que poderiam ser utilizados para democratizar e melhorar a vida humana". No ensaio de 1941, o filósofo mostra os problemas ocasionados pela implementação de uma nova racionalidade repressora da liberdade humana e as possibilidades de emancipação a partir de uma transformação do modo de funcionamento da sociedade capitalista.

\section{Técnica e racionalidade tecnológica}

No ensaio "Algumas implicações sociais da tecnologia moderna", editado por Douglas Kellner (1999), mas publicado originalmente em 1941, no periódico do Instituto de Pesquisa Social de Frankfurt, Herbert Marcuse apresenta sua primeira análise do avanço da técnica e da tecnologia nas sociedades modernas. $\mathrm{O}$ ensaio contém o princípio da teoria marcuseana sobre a tecnologia, que voltou a ser objeto de análise no livro A Ideologia da Sociedade Industrial, publicado originalmente em 1964. Marcuse foi um dos primeiros pesquisadores a realizar estudos críticos sobre os mecanismos de dominação a partir de uma racionalidade tecnológica que se transformou em racionalidade política, em curso ainda hoje. Os textos publicados pelo filósofo alemão sobre o tema "[...] expõem suas críticas penetrantes à tecnologia e análises dos modos pelos quais a tecnologia moderna está produzindo novas formas de sociedade e cultura com novas formas de controle social" (KELLNER, 
1999, p. 18). Nele o filósofo faz uma análise do desenvolvimento das forças produtivas e de como o ingresso da maquinaria no modo de produção modificou o processo de trabalho, a vida humana e a sociedade (PISANI, 2006). Segundo Pisani (2008, p. 5), Marcuse mostra que

[...] a tecnologia está criando novas formas de controle sociais em sua aliança com os poderes econômicos e políticos (indústria, Estado, aparato militar) e uma nova sociedade com um novo tipo de indivíduo, aquele que aceita o universo das coisas dadas, que se submete à eficácia e controle tecnológicos.

No ensaio, Marcuse apresenta uma definição de técnica e de tecnologia, a primeira como sendo um aparato técnico das indústrias da comunicação e um fator parcial do modo de produção. A tecnologia é caracterizada como "[...] modo de produção, como totalidade de instrumentos, dispositivos e invenções que caracterizam a era da máquina [...]", e também “[...] ao mesmo tempo, uma forma de organizar e perpetuar (ou modificar) as relações sociais, uma manifestação do pensamento e dos padrões de comportamento dominantes, um instrumento de controle e dominação" (MARCUSE, 1999, p. 73), constituindo-se na própria ideologia da sociedade industrial.

A técnica é compreendida como neutra, podendo ser utilizada tanto para a libertação quanto para a dominação do homem, bem como escassez ou abundância. Marcuse parte do princípio de que a técnica tem um potencial de libertar o homem do trabalho abstrato, porém, na sua atual caracterização, nas sociedades industriais é empregada pela racionalidade tecnológica como instrumento de exploração e dominação do homem pelo homem.

Segundo Soares (2004, p. 77), a máquina, instrumento de produção característico da Revolução Industrial, “[...] veio não somente demonstrar a capacidade humana de controlar a natureza, mas também melhorar ou piorar o mundo, dependendo do uso que se faz da técnica".

A tecnologia é percebida como instrumento e, ao mesmo tempo, forma de controle. É a totalidade dos objetos utilizados como dominação, é um processo social que, no percurso de seu desenvolvimento, criou uma nova racionalidade e, consequentemente, padrões de individualidade foram surgindo. $\mathrm{O}$ novo padrão de pensamento favorece os monopólios industriais e criou uma nova sociedade adaptada aos princípios da tecnologia. Marcuse diz que os indivíduos integram a tecnologia, "[...] não apenas como indivíduos que inventam ou mantêm a maquinaria, mas também como grupos sociais que direcionam sua aplicação e utilização" (MARCUSE, 1999, p. 73).

No texto de 1941, Herbert Marcuse descreve os padrões de individualidade e racionalidade tradicionais anteriores ao desenvolvimento da racionalidade tecnológica. O filósofo mostra que no processo de constituição da sociedade moderna, o individualismo, inerente ao sujeito econômico livre e pertencente à sociedade burguesa, foi sendo suprimido devido ao desenvolvimento dos novos padrões de racionalidade.

O indivíduo, antes do atual desenvolvimento tecnológico, valia-se de padrões e valores diferentes dos que prevaleceram na sociedade moderna. $\mathrm{O}$ indivíduo pertencente à sociedade burguesa dos séculos XVI e XVII era um ser racional plenamente capaz de descobrir as melhores formas de vida, individual e social, adequadas para o seu desenvolvimento. O sujeito livre e racional daquela época era aquele que não se deixava guiar pelos falsos padrões e valores impostos por autoridades externas. Desta forma, a racionalidade do indivíduo servia para concretizar a sua autonomia e para o desenvolvimento da sociedade. A sociedade tinha como função garantir a liberdade de ação racional dos indivíduos (MARCUSE, 1999). 
Para o autor, "[...] a sociedade liberal era considerada o ambiente adequado à racionalidade individualista" (MARCUSE, 1999, p. 76). Esta sociedade oferecia um ambiente social e econômico apropriado para o desenvolvimento da racionalidade crítica. A produção do sujeito econômico livre supria parte das necessidades da sociedade e era marca da individualidade destes indivíduos.

\begin{abstract}
No decorrer do tempo, no entanto, o processo de produção de mercadorias solapou a base econômica sobre a qual a racionalidade individualista se construiu. A mecanização e a racionalização forçaram o competidor mais fraco a submeter-se ao domínio das grandes empresas da indústria mecanizada que, ao estabelecer o domínio da sociedade sobre a natureza, aboliu o sujeito econômico livre. (MARCUSE, 1999, p. 76).
\end{abstract}

Segundo Marcuse (1999), apesar da individualidade não ter desaparecido, foi sendo inserida em um processo de organização e coordenação a partir do desenvolvimento do aparato tecnológico. Dentro dos mecanismos de coordenação da vida, a individualidade foi mantida enquanto necessária para o desempenho de determinadas atividades de produção.

A racionalidade tecnológica caracteriza-se como um modo de pensamento, que estabeleceu padrões de julgamento e levou os indivíduos a aceitarem e a introjetarem a lógica do aparato (PISANI, 2008). Com o desenvolvimento do capitalismo monopolista e também da racionalidade tecnológica, os padrões e valores da consciência individual foram sendo suprimidos.

Desta forma, uma 'mecânica do conformismo' se espalhou pela sociedade. A eficiência e o poder da sociedade tecnológica/industrial oprimiu o indivíduo, que gradualmente perdeu os traços característicos anteriores da racionalidade crítica (isto é, autonomia, discordância, poder de negação etc.), produzindo assim um declínio da individualidade e o que Marcuse mais tarde chamaria de 'sociedade unidimensional' e 'homem unidimensional'. (KELLNER, 1999, p. 26)

O indivíduo teve que se adaptar às exigências do novo método de produção, o trabalho humano se tonou suplementar ao da máquina. $\mathrm{O}$ avanço do individualismo, caracterizado pela racionalidade crítica capaz de encontrar os meios para o seu desenvolvimento tanto pessoal quanto social, foi transformado em eficiência altamente padronizada. Dessa forma, a liberdade do indivíduo foi dominada por uma nova racionalidade. Os empresários das grandes indústrias também foram afetados pela racionalidade tecnológica, pois os aparatos tecnológicos também definem as formas de produção. Os fatos que dirigiam as ações e os pensamentos do homem deixaram de ser o da natureza ou o da sociedade e passaram a estar subordinados aos dos processos de produção (MARCUSE, 1999).

Para Marcuse (1999), a nova racionalidade distingue-se das anteriores pela submissão que ela exige, a subjetividade humana foi sendo constantemente moldada para contribuir com o funcionamento do aparato e as relações humanas vieram a ser mediadas pelo processo da máquina.

Não há saída pessoal do aparato que mecanizou e padronizou o mundo. É um aparato racional, combinando a máxima eficiência com a máxima conveniência, economizando tempo e energia, eliminando o desperdício, adaptando todos os meios a um fim, antecipando as consequências, sustentando a calculabilidade e a segurança. (MARCUSE, 1999, p. 80)

Quanto mais a racionalidade individualista do sujeito autônomo foi sendo adaptada ao processo da máquina, mais ele se tornou submisso ao processo de dominação; "para a maioria da população, a liberdade anterior do sujeito econômico foi gradualmente submersa na eficiência com a 
qual ele desempenhava serviços a ele atribuídos" (MARCUSE, 1999, p. 78). O método de treinamento e ajuste do sujeito para utilização da maquinaria industrial ultrapassou o campo das indústrias e propagou-se para a ordem social, moldando os indivíduos dentro e fora do mundo do trabalho. "O mundo tinha se racionalizado a tal ponto, e esta racionalidade se tornou tal poder social, que o indivíduo não poderia fazer nada melhor do que adaptar-se sem reservas" (MARCUSE, 1999, p. $78)$.

Dessa forma, o homem viu-se em uma nova sociedade em que a tecnologia perpassa toda a realidade, desde o trabalho até mesmo os momentos de lazer. A modificação no modo de produção trouxe uma nova mentalidade, que está sendo difundida para conservação da estrutura capitalista.

Segundo Soares (2004, p. 80)

[...] Marcuse define a tecnologia como sendo um sistema de dominação ideológica, não existe uma coerção externa, oriunda da máquina, tolhendo a individualidade, mas uma racionalidade introjetada que se faz sentir em todas as esferas da vida [...]".

Devido a esse processo, a interiorização da racionalidade reforçou os mecanismos de dominação e estes se transformaram em métodos de autodisciplina e autocontrole. Esse acontecimento foi um dos principais responsáveis pelo enfraquecimento do pensamento crítico pós-revolução industrial. Outro fator importante foi a cooptação dos mecanismos de oposição pelo aparato tecnológico. Os valores da verdade individualista foram modificados quando incorporados pela racionalidade tecnológica e os seus ideais foram utilizados para afirmação dos conjuntos de verdade do aparato. Com conjunto de valores diferentes, a racionalidade tecnológica serve exclusivamente para o funcionamento e a manutenção da ordem social. Portanto, o homem passou a ficar subordinado às leis do aparato tecnológico que ele criou. $\mathrm{Na}$ era da padronização da produção, o homem se tornou, assim como as máquinas, apenas um fator parcial do modo de produção, um instrumento que pode ser substituído a qualquer momento (MARCUSE, 1999).

Com o desenvolvimento do modo de produção nos fins do século XIX, a contraposição entre os indivíduos e a sociedade, que anteriormente servia para reformar a sociedade com vistas a atender os interesses dos indivíduos, veio para justificar o afastamento do indivíduo do mundo social; a alma livre do sujeito autônomo tornou-se espaço de resignação.

A racionalidade tecnológica se desenvolveu a partir da Revolução Industrial; ela produziu uma nova mentalidade que permitiu uma aprimorada forma de dominação dos homens por outros homens e a cooptação dos meios de transformação condenou os indivíduos a uma servidão voluntária.

Segundo Aldous Huxley, no prefácio ao livro Admirável mundo novo, publicado em 1934, o amor à servidão só pode ser estabelecido mediante uma grande transformação na mentalidade e nos corpos dos indivíduos. Parece que foi exatamente esta transformação que a racionalidade tecnológica possibilitou. Os homens abdicaram de uma liberdade de construção da própria vida por uma ilusória promessa de bem-estar permanente pregado pelo capitalismo. A nova racionalidade é irracional, porque, ao mesmo tempo em que cria abundância, produz a escassez e a miséria, tornando o conforto um privilégio para poucos. Porém, para a manutenção do privilégio de poucos na sociedade industrial capitalista é necessária a exploração e dominação de todos os outros não privilegiados.

\section{Papel da Técnica}

No texto de 1941, Marcuse mostra de forma dialética as possibilidades de transformação da sociedade a partir da modificação do modo de utilização da técnica. O filósofo descreve 
contradições que podem proporcionar mudanças na estrutura da sociedade em prol do pleno desenvolvimento das potencialidades humana e, consequentemente, no fim da servidão.

[...] depois de documentar detalhadamente os modos pelos quais a tecnologia e a racionalidade tecnológica promovem o conformismo e minam a individualidade, Marcuse conclui seu estudo com uma visão de como a técnica pode produzir abundância para todos, eliminar a necessidade da labuta excessiva e do trabalho alienado, além de expandir o reino da liberdade. (KELLNER, 1999, p. 27)

Marcuse aponta que a técnica é um instrumento que tem a potencialidade de proporcionar a liberdade para o homem. Por ser neutra, ela só impede o desenvolvimento do indivíduo quando inserida em um processo de controle social e produção de escassez.

Ele salienta que o progresso tecnológico pode diminuir o tempo e a energia gastos para produção dos objetos necessários para a subsistência humana. Com a possibilidade de perder menos tempo de vida na produção e manutenção da sociedade, o homem pode dedicar-se ao seu pleno desenvolvimento, destinando menos tempo para produção das necessidades. Assim, poderia descansar e ser feliz sem que esses prazeres fossem intermediados por mecanismos de controle. "[...] sem estar preso à eficiência competitiva, o eu poderia crescer no reino da satisfação. O homem poderia encontrar-se consigo mesmo nas suas paixões" (MARCUSE, 1999, p. 103). E só mediante a utilização da técnica visando à preservação e melhoria da vida de todos os homens de forma igualitária é que a estrutura de exploração poderia ser rompida.

Para Soares (2004, p. 79),

[...] a racionalidade tecnológica é a pedra que obstrui o caminho dos homens para um mundo com uma organização social melhor estruturada. Ela produz nos homens um tipo de repressão mental que impede o projeto de uma sociedade emancipada e com valores diferentes dos capitalistas. Contudo, esse tipo de racionalidade que surgiu no seio do capitalismo ocidental pode ser eliminado se a técnica servir a âmbitos sociais.

A contradição da produção capitalista, que produz em larga escala mercadorias suficientes para satisfação das necessidades humanas, coexiste com grandes quantidades de excedentes em algumas regiões e, em outras, a escassez, evidenciando a má utilização da técnica. Porém, segundo Marcuse, essa contradição pode levar a uma ruptura da estrutura da sociedade e a uma adequada utilização dos aparatos tecnológicos. Soares (2004, p. 82) diz que "[...] a dominação e a emancipação caminham juntas, sendo o uso da técnica um fator determinante para que uma ou outra prevaleça" e que a mudança passaria pela criação de uma nova racionalidade que realize o potencial emancipador da técnica. Portando, o problema não é a técnica, que pode ser utilizada para vários fins, mas sim a racionalidade que a utiliza para manutenção do modo de produção capitalista.

\section{NOTAS}

1 Licenciado em Filosofia pela Universidade Federal do Tocantins-(UFT). Pós-graduando em Ensino Interdisciplinar em Infância e Direitos Humanos pela Universidade Federal de Goias-(UFG). E-mail: andref.freire@hotmail.com.

2 "Maio de 1968" foi um movimento estudantil que ocorreu na Europa, gerando vários protestos contra as universidades e contra os rumos que a sociedade estava tomando. 
3 “'...] o nome 'Escola de Frankfurt' refere-se simultaneamente a um grupo de intelectuais e a uma teoria social. Em verdade, esse termo surgiu posteriormente aos trabalhos mais significativos de Horkheimer, Adorno, Marcuse, Benjamin e Habermas [...]. (FREITAG, 1988, p. 9)

${ }^{4}$ Sob a direção de Marx Horkheirmer foi criada a Revista de Pesquisa Social, meio para publicação dos trabalhos dos membros e colaboradores do Instituto.

5 Partido Nacional Socialista dos Trabalhadores Alemães (NSDAP)

\section{REFERÊNCIAS BIBLIOGRÁFICAS}

FEENBERG, Andrew. Fenomenologia de Marcuse: lendo o capítulo seis de O Homem unidimensional. Tradução de Vanessa di Lego. Sem data de publicação. Disponível em: https://www.sfu.ca/ andrewf/One\%20Directional\%20Man.pdf. Acesso em: 25 de maio de 2016.

FREITAG, Barbara. A Teoria crítica: ontem e hoje. 2. ed. São Paulo: Brasiliense, 1988.

HUXLEY, Aldous. Admirável mundo novo. Tradução de Lino Vallandro e Vidal Serrano. São Paulo: Globo, 2009.

KLEIN, Stefan Fornos. Sobre a dominação e emancipação na teoria crítica de Herbert Marcuse. São Paulo: Universidade de São Paulo, São Paulo, 2006, 115f. Dissertação (Mestrado). Universidade de São Paulo.

KELLNER, Douglas. "O Marcuse desconhecido: novas descobertas nos arquivos”. In: MARCUSE, Herbert; KELLNER, Douglas (ed.), Tecnologia, Guerra e Fascismo. São Paulo: Fundação Editora da Unesp, 1999, p. 15-69.

MARCUSE, Herbert. Algumas implicações sociais da tecnologia moderna. In: MARCUSE, Herbert; KELLNER, Douglas (ed.), Tecnologia, Guerra e Fascismo. São Paulo: Fundação Editora da Unesp, 1999, p. 71-104.

PISANI, Maria M. A "máquina” como instrumento de controle na sociedade tecnológica: Herbert Marcuse crítico da tecnologia. In: Anais do Congresso Internacional A Indústria Cultural Hoje. Piracicaba: Unimep, 2006.

. Técnica, Ciência e Neutralidade no pensamento de Herbert Marcuse. São Carlos: Universidade Federal de São Carlos, 2008, 235f. Tese (Doutorado). Universidade Federal de São Carlos.

SOARES, Paulo Sérgio Gomes. Uma análise da técnica na concepção de Herbert Marcuse. In: Revista Olhar. São Carlos. Ano 6, vol. 10-11, 2004. p. 77-86. 